\title{
Emotional Intelligence and Perceived Stress among Dental Undergraduates in Delhi
}

\author{
Vipul Yadav ${ }^{1}$, Vikrant Mohanty ${ }^{2}$, Aswini Y Balappanavar ${ }^{3}$, Aditi Verma $^{4}$, Puneet Chahar ${ }^{5}$, Geetanjali Yadav $^{6}$
}

\begin{abstract}
Background: Emotional intelligence (EI) is understanding one's own feeling and able to handle those feelings without disturbing themselves. Medical schools are stressful and the ability to manage stress is a major factor of success for these students. The current study contributes further insight to body of research in El as it relates to students' stress in education, especially among dental undergraduates of Delhi.

Materials and methods: A cross-sectional, convenient sampling-based survey was conducted among 323 dental undergraduates from all the 3 dental Institutions across Delhi. The Schutte Emotional Intelligence and Perceived Stress scale instruments were administered to all the students of four professional years. The data analysis was done using SPSS V.17 and various statistical tests were used to determine significant difference. Results: No significant differences were found among gender as well as among professional groups for El. There was a significant difference (0.008) among gender with respect to perceived stress. Correlation analysis showed an inverse relationship between El and PS ( $r=-0.227)$ which was found to be statistically significant.

Conclusion: Training in dental education could be quite stressful due to their time-bound work, but regular student performance assessment and associated factors would allow understanding student behavior in handling situations.
\end{abstract}

Keywords: Dental undergraduates, Emotional intelligence, Perceived stress.

International Journal of Clinical Pediatric Dentistry (2020): 10.5005/jp-journals-10005-1789

\section{INTRODUCTION}

The customary method for identifying and measuring student success and their later success during their dental practice has been overcome by nontraditional cognitive skills. One approach to measure nontraditional characteristics is through emotional intelligence (EI). Research indicates that noncustomary methods of assessing intelligence such as emotional intelligence may be an enhanced predictor than customary psychometric methods like intelligence quotient and other uniform measures of educational achievement. Emotional intelligence involves one's ability to recognize accurately, appraise and express emotions, ability to access and/or create feelings when they facilitate thought, and the ability to appreciate one's emotions and its knowledge to control emotions to encourage emotional and intellectual growth. ${ }^{1}$

In recent years, emotional intelligence has developed great interest on its theoretical concept which to explore its relationship with various human capabilities. Emotional intelligence has now become a powerful tool to answer the question about the prediction of success stories about the leadership roles. ${ }^{2}$

Emotional intelligence now exists as a tool with those working in very stressful environment and managing high work pressure in different settings and in individuals with negative mood inductions, which may act as enhanced resilience. ${ }^{3}$ The studies have proved that emotional intelligence usually advances with age and experience. ${ }^{4}$ The various factors pertaining to emotional intelligence, such as leadership quality, communication skills, success, and ability to handle environmental stress, are all improved over a period of time and with increase in age. Dental and medical school may be stressful and the potential to cope with such a situation can be detrimental to success for these students. ${ }^{5}$

The academic success and well-being of an individual are well governed by the balance between academic and personal experiences. The results of one of the studies showed that there is
1-3,5 Department of Public Health Dentistry, Maulana Azad Institute of Dental Sciences, Delhi, India

${ }^{4}$ Department of Public Health Dentistry, Jamia Milia Islamia, Delhi, India

${ }^{6}$ Department of Genetics, Maharashi Dayanand University, Rohtak, Haryana, India

Corresponding Author: Geetanjali Yadav, Department of Genetics, Maharashi Dayanand University, Rohtak, Haryana, India, Phone: +91 9996115244, e-mail: geetanjalimdu@gmail.com

How to cite this article: Yadav V, Mohanty V, Balappanavar AY, et al. Emotional Intelligence and Perceived Stress among Dental Undergraduates in Delhi. Int J Clin Pediatr Dent 2020;13(4):344-347.

Source of support: Nil

Conflict of interest: None

a positive correlation between effective stress management with quality performance. ${ }^{6}$ In Medical and Dental Institutions, patients' outcomes can be improved by students with higher emotional intelligence scores.

Therefore, the institution should make a selection of dental and medical students based on the criterion of emotional intelligence. However, psychometric studies pertaining to El scales used for health care professionals (dentist, dental auxiliaries etc.) in the institution are rarely conducted which decides the individual level of coping and handling stress in their workplace. More commonly, in developing countries, individual assessment is solely done based on their academic excellence. ${ }^{5}$

These studies provide a basis to decide whether there is a need to expand the research pertaining to emotional intelligence in healthcare settings and healthcare education. This would further enhance the external validity of the study based on the 
generalizability of results and expand deeper into the fields of study such as education and training.

The student stress in dental education especially among dental undergraduates contributes to the current research related to $\mathrm{El}$ as it relates to students' stress in education, especially among undergraduates in the Indian context in the Indian dental educational system.

The objective of this study was to assess El and perceived stress among dental undergraduates as well to ascertain their relationship.

\section{Materials and Methods}

A cross-sectional survey was conducted from all three government dental institutions across Delhi with a convenience sample of 323 dental undergraduates. The sample size of 323 dental undergraduate students included both males and females from all the batches. Focus was placed on dental students of different years of their graduation, as they were most likely to have been exposed to different clinical and nonclinical procedures, which subsequently reflect their emotional intelligence and their stress level. Participation of the subjects in the survey was voluntary.

A validated self-administered questionnaire included sociodemographics (age, study years in school, and the name of the institution), perceived stress scale, and questions regarding emotional intelligence. Ethical approval was granted by the institutional ethical committee before the start of study.

El scale: it is a 33-item questionnaire developed by Schutte et al. with a 5-point Likert-type scale. ${ }^{7}$ It is a self-administered, structured, prevalidated questionnaire where the students have to read each and every statement and choose from among "strongly disagree," "disagree," " neutral," "agree," or "strongly agree" for every statement.

From the total 33 items in the model, thirteen items belonged to appraisal and expressions of the emotions, 10 items in the regulation of emotion category, and the remaining 10 items to the utilization of emotion category.

Out of 33 items, 5, 28, and 33 were reversed scored for crosschecking. ${ }^{8}$ The original PSS had 14 questions based on the theory of Lazarus which is related to stress appraisal (Lazarus and Folkman, 1994, as cited in Pau, et al., 2003). The PSS10 is a modified and miniature version of the original PSS 14, introduced by Sheldon Cohen (1988) which is a self-reported questionnaire that assesses individual's perceptions of stress that have occurred in the past month. The revised and modified versions of original PSS 14, that is, PSS-10 and PSS-4, were developed subsequently over a period of time (Cohen et al., 1983).

The PSS-10 has a fixed factorial structure and higher internal reliability and is thus preferred over PSS14 and PSS4 (Cohen et al. 1999). The participants have to give response on a 4-point Likert scale for each question of their personal perceived stress experiences during the past month. The final score will be obtained by reversing the score of four positive items $4,5,7$, and 8 out of total 10 items and then adding up all the scores.

The perceived stress score ranges from 0 to 40, with higher scores indicating greater stress. A score of PSS-10 than 13 indicate less stress, s score of 13-19 indicates moderate stress, and a score of 20 or more indicates high stress. The PSS-10 does not provide cut-off scores for different ratings of perceived stress as it is not considered to be a diagnostic tool.

The data were analyzed using SPSS version 17. Chi-squared test and Mann-Whitney test were applied to test the significance, and the confidence interval level was set at $95 \%$ with a $p$ value of 0.05 . Correlation analysis was done using Pearson's correlation.

\section{Results}

The response rate of the participants was $76.32 \%$. The total number of male participants was 116, while the number of female participants was 206 . The result of the study showed that the total number of undergraduate subjects were 323 . Out of which 116 were males while 207 were females. The mean age of the male subjects was 23.8 and that of females was 22.6. The El score ranged from 78 to 148 . The mean El score was $119.42 \pm 12.70$, while the mean PSS score was $20.04 \pm 5.32$. Emotional intelligence score was considered as high or low on the basis of $75 \%$ of the maximum El score.

The perceived stress score was categorized as 1, 2, and 3 with $1=0-19,2=20$, and $3=>20$. Figure 1 depicts that the emotional intelligence was higher in females (66.38\%) when compared to males (29.20), while the perceived stress was higher in males $(74.10 \%)$ when compared to females $(25.90 \%)$. There was a difference in high and low El scores among males and females, but it was found to be statistically nonsignificant ( $p=0.521$ ), while difference between perceived stress 1,2 , and 3 among males and females was at a statistically significant difference at $p=0.008$.

Table 1 shows the difference in emotional intelligence and perceived stress with different professional years. When emotional intelligence was compared with different professional years, the final-year undergraduate students found to have lowest emotional intelligence (18.13\%) followed by the third-year (22.64\%) and second-year (32.99\%) students and highest among the first-year students (35.46\%), while the perceived stress gradually increased from the first year to the final year. The overall perceived stress was greater among final-year students (38.71\%) and the lowest was amongst first-year students (17.43\%).

The overall difference among the emotional intelligence, perceived stress with the different professional year students were statistically nonsignificant $(\mathrm{pEI}=0.261$ and $\mathrm{pPS}=0.726$ ). The students who were in the preadolescence age ( $<19$ years) group were found to have a higher emotional intelligence (65.84\%) while those in the postadolescence age group were having a lower emotional intelligence (23.39\%), while the perceived stress was highest among the postadolescence age group (76.61\%) and the lowest being among the preadolescence age group (23.39\%).

There was a difference in the age group with the El and PS, but it was statistically significant with the PS ( $p=0.0045)$ only. Table 2 shows the negative correlation between El and PS $\left(r=-0.227^{*}\right)$ which was found to be statistically highly significant $(p=0.00)$.

\section{Discussion}

This is the first self-administered questionnaire based survey among dental undergraduates in Delhi assessing the association between El and PS.

The objective of the study was to find whether there is any association between El and PS among dental undergraduates. The study done by Humphris et al. among dental undergraduates regarding perceived stress concluded that the emotional stress contributed higher among dental undergraduates than medical undergradautes, ${ }^{9}$ which proved that training in dental schools is a highly stressful exercise. 


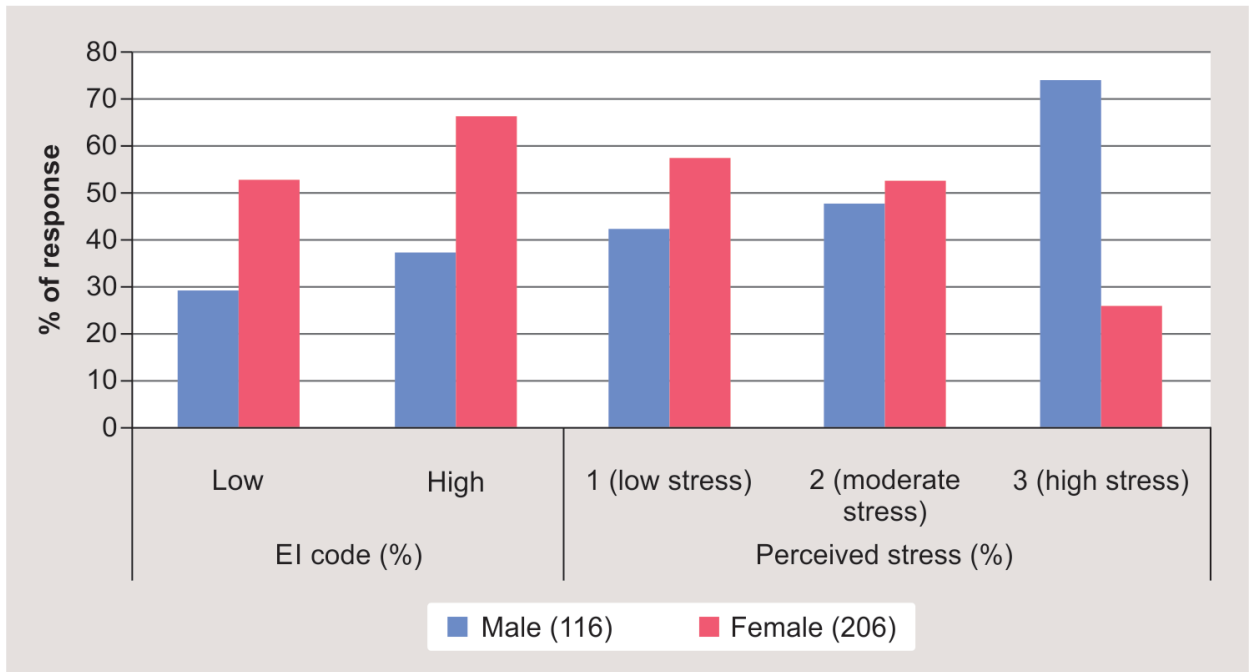

Fig. 1: Influence of gender with emotional intelligence and perceived stress. The difference among emotional intelligence among males and females was found to be statistically non- significant $(p=0.521)$ while for the perceived stress, there was a highly statistical significant difference $\left(0.008^{*}\right)$

Table 1: Influence of professional year and age with emotional intelligence and perceived stress among dental undergraduates

\begin{tabular}{|c|c|c|c|c|c|c|c|}
\hline Variable & \multicolumn{3}{|c|}{ El code (\%) } & \multicolumn{4}{|c|}{ Perceived stress (\%) } \\
\hline Profyear & Low & High & & 1 & 2 & 3 & \\
\hline 1 & 21.99 & 37.03 & \multirow{4}{*}{$\begin{array}{l}\text { Chi square }=1.319 \\
p=0.260\end{array}$} & 17.43 & 22.03 & 17.11 & \multirow{4}{*}{$\begin{array}{l}\text { Chi square }=4.010 \\
p \text { value }=0.725\end{array}$} \\
\hline 2 & 25.46 & 35.66 & & 22.12 & 18.94 & 20.46 & \\
\hline 3 & 22.64 & 26.44 & & 18.18 & 22.8 & 30.12 & \\
\hline 4 & 18.13 & 20.88 & & 24.25 & 29.84 & 38.11 & \\
\hline Age & Low & High & & 1 & 2 & 3 & \\
\hline 1 & 23.67 & 31.03 & \multirow{2}{*}{$\begin{array}{l}\text { Mann-Whitney }=-1.439 \\
p=0.150\end{array}$} & 51.52 & 23.49 & 23.39 & \multirow{2}{*}{$\begin{array}{l}\text { Mann-Whitney }= \\
-2.007, p: 0.045\end{array}$} \\
\hline 2 & 76.33 & 68.97 & & 48.48 & 76.61 & 76.51 & \\
\hline
\end{tabular}

Table 2: Correlation of emotional intelligence and perceived stress

\begin{tabular}{llll}
\hline \multicolumn{3}{c}{ Correlations } \\
\hline & & EI & PS \\
\hline EI & Pearson's correlation & 1 & -0.227 \\
& Sig. (2-tailed) & & 0.000 \\
& N & 323 & 323 \\
PS & Pearson's correlation & -0.227 & 1 \\
& Sig. (2-tailed) & 0.000 & \\
& N & 323 & 323 \\
\hline
\end{tabular}

In our study, females scored less on the El scale than males which was in accordance with one of the studies by Saklofske et al. ${ }^{10}$ which might be due to ability of the females to perceive emotions slightly superior to males, which was in accordance with the study done among dental undergraduates in England.

The males had a higher stress as compared to females, which is in accordance with the study done by Salovey et al. ${ }^{11}$ which might be due to the intensive workload leading to increased pressure arising from the absence of relaxation and attainment of career aspiration in academics. With respect to gender, females were more sensitive, empathic, and adaptable than males in the perspective of interpersonal social skills, which is closely linked to El. According to the year of study, the third- and final-year students (seniors) scored less El scores than the first- and secondyear (juniors) students.
Lower El scores were associated with perceived stress. The students from the final and third years have to carry out their routine diagnostic and clinical dental procedures which places them in direct contact with the patients as per the Dental Council of India syllabus. This excessive burden on dental students allows them to complete their clinical quota within well-stipulated time as per the curriculum, to appear in the professional examination and for the future job access. ${ }^{12}$ This excessive stress is well tolerated by emotional intelligence as it plays a very important role in shaping the behavior and experiencing students' psychological stress. However, on the other hand, students with less patient exposure were more likely to perceive stress than their counterparts (Humphris et al. ${ }^{9}$ ).

In contrast to this result, students in their lower grades were more experiencing stress than the higher-grade students as reported by Newton et al. ${ }^{13}$ However, the evidence from the literature reports that clinical factors such as coping with challenging or uncooperative patients, panic situation arising due to failing in examinations and while during treatment, and fulfilling clinical necessities among dental students and general dental practitioners are directly associated with perceived stress.

The result of our study demonstrated that the increase in age from preadolescence ( $<19$ years) to postadolescence ( $>19$ years), there was a decrease in emotional intelligence and increase in perceived stress level, which was similar to the study done by Lorenzo et al. ${ }^{14}$ Age plays a very crucial and important role in 
emotional intelligence, as assessed by previous literature on El as it increases with age.

The finding from the current study and evidence back from literature supports that core components of El, mainly the ability of an individual to cope with personal emotions, is one of the crucial factors in reducing the perceived level of stress. Thus, it can be concluded that emotional intelligence is just an adaptation to the new environment. As people grow, they have more opportunity to learn about emotions and the gradations of emotions, increase emotional vocabulary, and experience more and more varied life situations. Perhaps they accumulate more feedback and integrate this into greater self-awareness. ${ }^{14}$ Occupational stress was negatively associated with El.

This is because a maximum number of participants could not regulate their emotions and are unaware of it which would further decrease their coping abilities to deal with occupational stress. As well, they experience a low confidence in their capabilities which may have the tendency to look at things as if they are tougher than they really are. ${ }^{15}$ Studies done by Limonero et al. ${ }^{16}$ analyzed the stress associated with nursing professionals and it was hypothesized that there was negative association of stress with emotional repair among nursing. That is, nursing professionals being younger adults know about their emotions, thoughts, feelings and situation which aggravate theses emotions, are able to manage these emotions, and have lower levels of stress in their work.

Results from the present study hypothesized that those individuals working in dental environment bear more stress as their capability to deal with emotional repair is less as compared to their counterparts. The dental professionals in their workplace due to higher workload are highly dissatisfied that leads to demotivation and decrease in the quality of work.

Dentistry as a profession is always subjected to higher degrees of stress, partly as it requires both hard and soft skills in clinical scenario along with the completion of clinical quota within the stipulated time, high pressure from teachers and seniors, and lack of autonomy and lack of help from seniors, making these professionals a "perfect target" for the burnout syndrome in their work. Various measures have been proposed in the literature for scheming stress in dental students. ${ }^{17}$

\section{Conclusion}

This study examined the link between perceived stress and emotional intelligence in dental students exposed to different years of training. It was found that those in the third year and final year were found to have low El and higher stress.

Training in dental education could be quite stressful due to their time-bound work, but regular student performance assessment and associated factors would allow the understanding of student behavior in handling situations. Stress prevention and intervention programs within the dental curriculum are the best ways to manage the most common sources of stress among dental students.

\section{References}

1. Goleman D. Working with emotional intelligence. New York: Bantam; 1998.

2. Mayer JD, Salovey $P$, Caruso DR, et al. Measuring emotional intelligence with the MSCEIT v2.0. Emotion 2003;3(1):97-105. DOI: 10.1037/1528-3542.3.1.97.

3. Krishnakumar R, Lalitha S. A study on emotional intelligence and occupational stress. Int J Multidiscip Curr Res 2014;2:633-636.

4. Bar-On R. Emotional and social intelligence: insights from the emotional quotient inventory (EQ-i). In: Bar-On R, Parker JDA, ed. Handbook of emotional intelligence. San Francisco, CA: Jossey-Bass; 2000. pp. 12-17.

5. Pau AKH, Croucher R. Emotional intelligence and perceived stress in dental undergraduates. J Dent Educ 2003;67(9):1023-1028. DOI: 10.1002/j.0022-0337.2003.67.9.tb03685.x.

6. Stewart SM, Lam TH, Betson C, et al. A prospective analysis of stress and academic performance in the first two years of medical school. Med Educ 1999;33(4):243-250. DOI: 10.1046/j.1365-2923.1999. |00294.x.

7. Schutte NS, Malouff JM, Hall LE, et al. Development and validation of a measure of emotional intelligence. Pers Individ Differ 1998;25: 167-177. DOI: 10.1016/S0191-8869(98)00001-4.

8. Cohen S, Williamson G. Perceived stress in a probability sample of the United States. In: Spacapan S, Oskamp S, ed. The social psychology of health: Claremont Symposium on Applied Social Psychology. Newbury Park, CA: Sage; 1988.

9. Humphris G, Blinkhorn A, Freeman R, et al. Psychological stress in undergraduate dental students: baseline results from seven European dental schools. Eur J Dent Educ 2002;6(1):22-29. DOI: 10.1034/j.1600-0579.2002.060105.x.

10. Saklofske DH, Austin EJ, Minski PS. Factor structure and validity of a trait emotional intelligence measure. Pers Individ Differ 2003;34: 707-721. DOI: 10.1016/S0191-8869(02)00056-9.

11. Salovey P, Mayer JD. Emotional intelligence. Imagin Cogn Pers 1990;9(3):185-211. DOI: 10.2190/DUGG-P24E-52WK-6CDG.

12. Garbee WH, Zucker SB, Selby GR. Perceived sources of stress among dental students. J Am Dent Assoc 1980;100(6):853-857. DOI: 10.14219/ jada.archive.1980.0279.

13. Newton JT, Baghaienaini F, Goodwin SR, et al. Stress in dental school: a survey of students. Dent Update 1994;21(4):162-164.

14. Lorenzo F, Ghini M, Freedman J, et al. Organizational Engagement, Emotional Intelligence and Performance, Six Seconds (6sec.org/ amadori) 2013.

15. Ciarrochi J, Deane FP, Anderson S. Emotional intelligence moderates the relationship between stress and mental health. Pers Individ Differ 2002;32:197-209. DOI: 10.1016/S0191-8869(01)00012-5.

16. Limonero TS. Analysis of the relationship between emotional intelligence and stress caused by the Organisation: a study of nurses. Bus Intell J 2012;5(2):334-337.

17. Schwartz RM, Eigenbrode CR, Cantor O. A comprehensive stressreduction program for dental students. J Dent Educ 1984;48(4): 203-207. DOI: 10.1002/j.0022-0337.1984.48.4.tb01776.x. 